\title{
Availability Does Not Mean Utilisation: Analysis of a large Micro Health Insurance Programme in Pakistan
}

\author{
Abdur Rehman Cheema ${ }^{1}$, Shehla Zaidi ${ }^{2}$, Rabia Najmi ${ }^{2}$, Fazal Ali Khan ${ }^{1}$, Sultana Ali Kori ${ }^{1} \&$ Nadir Ali Shah ${ }^{1}$ \\ ${ }^{1}$ Rural Support Programmes Network, Islamabad, Pakistan \\ ${ }^{2}$ Department of Community Health Sciences, Aga Khan University, Karachi, Pakistan \\ Correspondence: Abdur Rehman Cheema, Rural Support Programmes Network (RSPN), 3rd Floor, IRM Complex, \\ Plot \#7, Sunrise Avenue (off Park Road), Near COMSATS University, Islamabad, Pakistan. E-mail: \\ arehmancheema@gmail.com; fazal@rspn.org.pk
}

Received: April 20, 2020 Accepted: June 25, 2020 Online Published: July 20, 2020

doi:10.5539/gjhs.v12n10p145 URL: https://doi.org/10.5539/gjhs.v12n10p14

\begin{abstract}
In recent years, several Micro Health Insurance (MHI) schemes have been initiated in low- and middle-income countries (LMIC) to meet the universal health coverage targets. Evidence on the utilization of these MHI schemes is scarce. Field experiences and lesson learning is crucial to effectively increase access to health care and offer protection against catastrophic health expenditure to the poorest population through the MHI schemes. This paper analyzes community utilization and factors affecting utilization of an MHI provided to the poorest rural households in eight districts of Sindh province of Pakistan. This initiative is part of a larger pro-poor European Union (EU) funded Sindh Union Council and Community Economic Strengthening Support (SUCCESS) Programme implemented by the Rural Support Programs (RSPs). The analysis draws on insurance utilization records and an internal assessment report by the RSPs Network (RSPN). The analysis provides qualitative experiences of the community, empanelled health care providers, the insurance agency and frontline management staff. Our analysis revealed that the overall utilization was very low $(0.42 \%)$ and the highest number of cases treated at the hospital were of women utilizing obstetric and gynaecology related care. The scheme was noted to prevent catastrophic health expenditure in households that were able to successfully utilize the scheme. Key factors affecting utilization were identified to be around i) awareness creation, ii) distance to empanelled hospitals, and iii) access issues at the health facility level. We aim to add to the knowledge base around MHI for policy makers to design and implement more informed initiatives in the future.
\end{abstract}

Keywords:health financing, micro health insurance, rural, sustainable development, Pakistan, utilization

\section{Introduction}

Micro Health Insurance (MHI) schemes are one of the initiatives that have been increasingly experimented in Low- and middle-income countries (LMICs) to enhance access to health services for underserved community groups by reducing out of pocket (OOP) expenditure (Horton \& Das, 2015; Meessen et al., 2019; Savedoff, de Ferranti, Smith, \& Fan, 2012; United Nations, 2016). These have gained salience in recent times as a financing option for progression towards universal health coverage. MHIs also contribute to Sustainable Development Goals 3 that advocates implementing financial protection measures to reduce out-of-pocket expenditure for the poor (United Nations, 2016).

MHI schemes provide a limited benefits package to rural and low-income communities in countries that have yet to design and effectively implement a government-led national insurance scheme (Churchill, 2006; Churchill \& McCord, 2012; Purohit, 2014; Tabor, 2005). They differ from the National Health Insurance (NHI) schemes in that they are a different model for protection where the decisions lie at the local level i.e. with the community. This makes it possible to reach the self-employed population and introduce the concept of health insurance. In contrast, NHI is typically controlled centrally by government decisions on enrolment, regulation, premiums and benefits plans. MHI has been known to support the national health insurance in various capacities, as a substitute for when NHI is absent e.g. Bangladesh or when certain poor are excluded from government schemes as seen in India; complementary to the NHI where they may form partnerships for marketing, distribution, identification of enrolees, distribution and claims processing asin the case of Kenya and Philippines; supplementary to the NHI schemes, offerings benefits that enhance the NHI scheme for e.g. OPD care coverage, loss of wages and transport cost cover such as in Kenya Philippines and India; or serve as a foundation to scale up UHC initiative as seen in Ghana and 
Thailand (Kimball, Phily, Folsom, Lagomarsino, \& Holtz, 2013). Sometimes MHI is implemented in parallel to government-supported national insurance schemes, focusing mainly on the self-employed sector which is poorly covered informal insurance schemes (Bitran, 2014; Bredenkamp et al., 2015; Kimball et al., 2013; Reich et al., 2016; Wagstaff, Nguyen, Dao, \& Bales, 2016).

Global evidence underscores how the demand for health insurance affects the access to services (Bitran, 2014; Comfort, Peterson, \& Hatt, 2013; Criel \& Waelkens, 2003; Khan \& Ahmed, 2013; Levine, Polimeni, \& Ramage, 2016; Mathauer, Schmidt, \& Wenyaa, 2008; H. Nguyen \& Knowles, 2010; Schneider \& Diop, 2001; Thornton et al., 2010; Wagstaff, 2007). Demand for insurance increases after awareness and communication interventions (Abduljawad \& Al-Assaf, 2011). Furthermore, a causal link has been reported between demand and expected benefits offered (H. Nguyen \& Knowles, 2010) with demand decreasing during the post treatment phase. Micro Health insurance was observed to have a significant effect on improving equity, reducing out of pocket payment, improving service utilization (especially inpatient services) and reducing the risk of catastrophic health expenditure. At the same time challenges of low enrolment, questionable quality of healthcare and accessibility of local healthcare service provider's accessibility have been reported (Jooma \& Jalal, 2012; Mehmood, Rowther, Kobusingye, \& Hyder, 2018; Tabor, 2005; Taneja \& Sihare, 2011). Concerns have been raised that unless MHI's are contextualised into the unique social, cultural and economic context of the local communities (Capuno, Kraft, Quimbo, Tan Jr, \& Wagstaff, 2016; Panda, Chakraborty, \& Dror, 2015; Wagstaff et al., 2016) sustainability of the MHI schemes beyond project life will be challenging.

In Pakistan, at least five micro-insurance schemes have been implemented since 2005 (Box 1) by large NGOs in partnership with insurance agencies. However, their experience has not been well published. Importantly a national health insurance initiative called the Prime Ministers National Health Insurance Scheme later renamed Sehat Sahulat Program (SSP) was launched in 2015 and covers 84 districts and 6.7 million households to date, with plans to be upscaled to all districts of Pakistan (Government of Pakistan). Pakistan's MHIs and the government led NHI share similarity of design addressing at the very poor, usually through explicit poverty scorecard-based targeting and a service package centred on inpatient admissions. There is a paucity of information from existing MHI pilots in Pakistan, on utilization and underlying influencing factors, including client experiences. Client perspectives on usefulness and usability of MHI schemes are critical to feed into the design of MHI scale up and enhance uptake by local communities. This is extremely important to transform lesson learnt to optimise the effects of the recently started NHI scheme, currently in initial stages but with plans to be substantially upscaled.

Box 1. Health Insurance schemes launched since 2005 in Pakistan

\section{RSPN-Adamjee Health Micro Insurance, 2005 (RSPN, 2008-09)}

- Launched for the low-income rural population across the country it was the country's first MHI initiative

- Provided hospitalization and accidental death coverage

First Micro Insurance Agency (FMiA), 2007 (AKDN)

- Formed by Aga Khan Development Network for the Northern Areas

- Provided cover for hospitalization as well as a number of curative out-patient cases

Naya Jeevan Health micro insurance, 2011 (Naya Jeevan)

- Launched for the low-income households in Karachi for quality health facilities

- Provided cover for hospitalization and outpatient services 20 days before and after hospitalization

Waseela-e-Sehat, 2012 (Waseela-e-Sehet, Government of Pakistan)

- Pilot project launched in Faisalabad district, under the micro health insurance scheme by Benazir Income Support Programme (BISP)

- Provided covered hospitalization for up to 6 members of a household at eight empanelled hospitals

Social health protection initiative (SHPI), 2011 (Government of Khyber Pakhtunkhwa)

- Launched by the Government of Khyber Pakhtunkhwa covered all districts by 2016

- Provided in-patient secondary care cover, limited tertiary cover, outpatient maternity and Cancer Care in addition to transportation and burial allowance.

Sehat Sahulat Programme (SSP), 2015 (Government of Pakistan)

- National level initiative rolled out by Pakistan's Federal, Provincial and Regional Governments

- Provides financial protection to the poor, disabled and transgender population against catastrophic health expenditure. 
This paper analyzes community utilization of an MHI provided to the poor rural households in Sindh province of Pakistan, as part of a larger pro-poor local community development initiative. The European Union (EU) supported MHI scheme was implemented by a large national NGOs the Rural Support Programs (RSPs) across eight districts of Sindh providing coverage for hospitalization and transport allowance to the poorest population sub-groups over 2017-18. We investigate how well the scheme was utilized, what it was utilized for and the key factors affecting utilization. The analysis draws on programmatic records of patient utilization and claims of MHI scheme by the enrolled population over May 2017-July 2018, an internal assessment report (Rural Support programme Network, 2018a). The internal report provides qualitative experiences of users and non-users, empanelled health care providers, the insurance agency and frontline management staff of the RSPs.

\section{Sindh's Pro-Poor Health Card Scheme}

This MHI initiative was part of a larger EU funded Sindh Union Council and Community Strengthening Support (SUCCESS) Programme aimed at reducing poverty at the household level. SUCCESS program was rolled out in eight districts in Sindh over six years from 2015 to 2021 by RSPs working in Sindh. Women empowerment and gender equality underpinned the entire program and initiatives under SUCCESS included Social Mobilization, Community Investment Fund, Micro Health Insurance (MHI), Income Generating Grants, Technical and Vocational Skills Training (TVST), Community Physical Infrastructure (CPI) and Research and Advocacy and Communication. All interventions were linked to women's participation in Community Organizations (COs). The hallmark of the SUCCESS program was the extent of investment in community organization at the grassroot level. Community Organizations (COs) were fostered typically comprising of 15-20 women members and was a neighbourhood level group. COs came together into a Village Organization (VOs) to plan and coordinate activities, whereas representatives from the VOs form the Local Support Organization (LSO) at the union council level. These local level governance bodies owned and operated by the members of the community had a primary function of identifying and solving issues in the community with assistance from the government and development partners.

Setting: The MHI scheme was introduced in Kamber Shahdad Kot, Larkana, Dadu, Jamshoro, Matiari, Sujawal, Tando Allahyar and Tando Muhammad Khan (TMK). These districts account for about 26 percent of the rural population of Sindh (Rural Support programmes Network, 2017-18) and have one of the highest concentrations of poor households (MICS, 2014). A significant portion of the population in these districts lacks access to frontline services for diarrhoea, malaria and deliveries (Table 1). The MHI however, did not cover for primary care services.

Table 1. Heath seeking behaviour in MHI districts

\begin{tabular}{|c|c|c|c|c|c|c|c|}
\hline \multirow[t]{3}{*}{ District } & $\begin{array}{l}\text { Children }<5 \\
\text { for whom no }\end{array}$ & $\begin{array}{l}\text { Children }<5 \\
\text { for whom no }\end{array}$ & $\begin{array}{l}\text { Children }<5 \\
\text { for whom No }\end{array}$ & \multirow{3}{*}{$\begin{array}{l}\text { Delivered in } \\
\text { a private } \\
\text { health } \\
\text { facility } \%\end{array}$} & \multirow{3}{*}{$\begin{array}{l}\text { Percent } \\
\text { delivered by } \\
\text { C-section }\end{array}$} & \multirow{3}{*}{$\begin{array}{l}\text { Post-partum } \\
\text { care } \\
\text { requiring 1-2 } \\
\text { days of stay } \\
\text { in a health } \\
\text { facility }\end{array}$} & \multirow{3}{*}{$\begin{array}{l}\text { Post-partum } \\
\text { care } \\
\text { requiring } 3 \\
\text { or more days } \\
\text { of stay in a } \\
\text { health } \\
\text { facility }\end{array}$} \\
\hline & $\begin{array}{l}\text { advice or } \\
\text { treatment }\end{array}$ & $\begin{array}{l}\text { advice or } \\
\text { treatment }\end{array}$ & $\begin{array}{l}\text { advice or } \\
\text { treatment }\end{array}$ & & & & \\
\hline & $\begin{array}{l}\text { was sought } \\
\text { for } \\
\text { diarrhoea } \%\end{array}$ & $\begin{array}{l}\text { was sought } \\
\text { during } \\
\text { malaria } \%\end{array}$ & $\begin{array}{l}\text { was sought } \\
\text { for ARI } \%\end{array}$ & & & & \\
\hline Kamber & 26.2 & 32.0 & 30.8 & 40.7 & 9.0 & 14.8 & 16.5 \\
\hline \multicolumn{8}{|l|}{ Shahdad Kot } \\
\hline Larkana & 30.7 & 20.1 & 14.3 & 38.8 & 13.1 & 13.8 & 19.7 \\
\hline Dadu & 31.5 & 24.4 & 12.1 & 33.0 & 12.2 & 19.6 & 26.4 \\
\hline Jamshoro & 14.9 & 23.3 & 20.0 & 31.6 & 12.1 & 13.2 & 19.5 \\
\hline Matiari & 23.6 & 26.1 & 18.2 & 35.2 & 22.5 & 19.2 & 27.3 \\
\hline Sujawal & 16.0 & 26.6 & 31.0 & 40.3 & 9.0 & 9.0 & 18.2 \\
\hline Tando Allahyar & 15.3 & 13.7 & 16.2 & 50.9 & 16.6 & 11.7 & 22.5 \\
\hline Tando & 36.9 & 30.8 & 20.9 & 53.3 & 11.2 & 5.9 & 15.6 \\
\hline \multicolumn{8}{|l|}{ Muhammad } \\
\hline Khan & & & & & & & \\
\hline
\end{tabular}

Source: Multiple Indicator Cluster Survey (MICS) 2014. 
Beneficiaries: A poverty scorecard survey was conducted in the eight selected districts in 2016 prior to the start of MHI (Rural Support Programmes Network, 2016). The Poverty Score Card (PSC), a tested and cost-effective tool developed by the World Bank assigns a score of between 0-100 to each household based on socio-economic indicators. A score of " 0 score" reflects the likelihood of being the poorest and a score of " 100 " means the likelihood of being the "richest". The households that scored between 0-23 were categorized as poor households with further breakdown into "extremely poor" (0-11), "chronically poor" (12-18) and "transitory poor" (19-23) (Table 2).

Of 850,000 households surveyed, 475,000 households (56 percent) were in the PSC $0-23$ (or poor) category and 110,463 in the poorest category scoring only $0-11$ (Table 2 ). These were essentially landless, not-literate, daily wage earners that worked primarily in the agricultural and farming jobs. About half of them owned cattle and live-stock averaging 0.8 cattle and goat heads per households and $81 \%$ of men and $71 \%$ of the women had Computerized National Identity Cards (CNICs) but less than one percent had birth certificates. Nearly half of them (48\%) did not have a toilet in the house and only 11 percent had a flush toilet (Rural Support Programmes Network, 2018b). The poorest households were enrolled in the scheme if the woman of the household was a member of the program community organization $(\mathrm{CO})$.

Table 2. Classification of households according to the poverty scorecard

\begin{tabular}{lll}
\hline PSC Score & Category & $\begin{array}{l}\text { Number of Households in the } \\
\text { SUCCESS districts }\end{array}$ \\
\hline PSC 0-11 & Extremely poor or ultra-poor & $110,463(13 \%)$ \\
\hline PSC 12-18 & Chronically poor & $201,682(23.73 \%)$ \\
\hline PSC 19-23 & Transitory poor & $163,112(19.2 \%)$ \\
\hline PSC 24-34 & Transitory vulnerable & $241,299(28.4 \%)$ \\
\hline PSC 35-40 & Transitory non-poor & $123,193(14.5 \%)$ \\
\hline PSC 41-100 & Non-poor & $10,005(1.18 \%)$ \\
\hline Total & & $849,754(100 \%)$ \\
\hline
\end{tabular}

Source: Poverty Score Card Survey Results, RSPN 2016.

Enrollment: The insurance holders were women of the community who were also members of the CO. If the insurance holder was married the beneficiaries would include herself, her husband, all children under 18 years, parents in law, and sisters in law under the age of 18 years. If she was single, the household beneficiaries included her parents and siblings under the age of 18 years. To receive the MHI cards the insurance holder was required to present her CNIC. One MHI card was issued by the insurance company per household to be shared by all eligible members.

Premium: The insurance company was paid, a premium of Pak Rs. 1,000/- per household (average poor HH size 7.4) per year by the SUCCESS project to cover in-patient services for the targeted households at empanelled hospitals. This premium rate is fixed for a period of 5 years (2016-2021). There was no user fee attached to the services.

Service Providers and Benefit Package: A total of 20 private hospitals in the eight program districts qualified for the scheme based on assessment by the insurance provider using a minimum service delivery standard checklist. As part of the contractual agreement between the insurance scheme and the SUCCESS program implementing RSPs, camps in the community were to be organized by the insurance provider to create awareness on MHI; attract more enrollment and encourage utilization by existing card holders. The benefit package comprised of inpatient services included hospital admission for at least 24 hours due to sickness or accidents; assisted normal deliveries and surgical deliveries; doctors fee; medicines; laboratory tests and surgeries up to a total of Pak Rs. 25,000 for each eligible beneficiary. All additional payments had to be borne by the patient. Outpatient services were not covered by the scheme. The scheme also covers transport allowance for travel to the hospital and a one-time cash payment in case of insurance holder's death, dismemberment and complete or partial blindness. In case of emergency, if the beneficiary was treated at a hospital, not on the panel, the expense was claimable up to Pak Rs. 25,000. To utilize these services at the empanelled hospital, the MHI card and the insurance holders' CNIC was 
required to be presented to the hospital admission staff.

\section{Methods}

The RSPN internal study that forms the basis of this paper employed qualitative case study research design drawing on the analysis of primary data (interviews and focus group discussions) and secondary data, mainly of the insurance provider. The study was conceived and planned in July 2018 and the implementing RSPs were taken into confidence. Six interviews and two focus group discussions were conducted in Sindhi and Urdu languages in September 2018 by the authors and a field assistant from RSPN. The study participants included RSP (4) and insurance provider (1) officials dealing with MHI. The focus group discussions were held one each with the users and non-users of MHI card, respectively. The insurance users were asked about their experience of using the insurance in terms of access to hospital, costs and benefits. The non-users were asked about the factors that discouraged them to utilize the insurance when it was needed. The programme implementing RSPs representatives were asked about their reflections on the design, implementation and utilization of the insurance provision. The insurance provider was asked about its perspective about the extremely low utilization of the insurance provision. Data analysis was carried out through continuous review, coding and category development based on emerging themes. This paper also draws on the programmatic records of patient utilization and claims of MHI scheme by the enrolled population, obtained from the insurance provider.

\section{Results}

Claims by Insurance Beneficiaries: The claims assessment was first carried out in August 2018 nearly a year and a half after the launch of the MHI initiative. Registration of members started in March 2017 and peaked around May of the same year. Data covering the 14 months from May 2017 until July 2018 was used for analysis. It showed district wise enrollments of individuals, the percentage who utilized services, and the claim ratio to premium percentage. The overall utilization in all eight SUCCESS programme districts was only $0.42 \%$. For a community-driven development programme of this scale that had several supporting initiatives including social mobilization, these results were well below expectation. All districts had similarly low utilization with Jamshoro having the highest percentage utilization $(1.18 \%$ ) by the beneficiaries followed by Larkana at $0.56 \%$. The districts with higher concentration of private hospitals with lowest rates seen in Matiari $(0.05 \%)$, Tando Muhammad Khan $(0.14 \%)$ and Tando Allahyar $(0.07 \%)$ where there is a very sparse presence of private hospitals.

The total claims ratio to premium was at $28.86 \%$ as shown in Table 3 . This figure was very favourable for the insurance provider as over $70 \%$ of the premium paid to the insurance provider was spared for administrative costs and profit. The only exception was Jamshoro district where $1.18 \%$ utilization by the beneficiaries resulted in $101.96 \%$ claims ratio to premium highlighting a loss for the insurance provider.

Table 3. Utilization of MHI and Claim to Premium Ratio up to July 2018

\begin{tabular}{llll}
\hline \multirow{2}{*}{ Districts } & Beneficiaries & \multicolumn{1}{c}{$\begin{array}{c}\text { Claim ratio to } \\
\text { premium (\%) }\end{array}$} \\
\cline { 2 - 4 } & Enrolled (n) & Treated (n\%) & 5.50 \\
\hline Tando Muhammad Khan & 52,466 & $73(0.14)$ & 16.13 \\
\hline Sujawal & 110,215 & $564(0.51)$ & 3.06 \\
\hline Matiari & 31,587 & $16(0.05)$ & 3.82 \\
\hline Tando Allahyar & 46,688 & $34(0.07)$ & 50.36 \\
\hline Larkana & 60,020 & $335(0.56)$ & 20.62 \\
\hline Kamber Shahdadkot & 101,822 & $343(0.34)$ & 101.96 \\
\hline Jamshoro & 77,472 & $915(1.18)$ & 33.16 \\
\hline Dadu & 188,915 & $535(0.28)$ & 28.86 \\
\hline Total & 669,184 & $2,815(0.42)$ & \\
\hline Source: & & & 286 \\
\hline
\end{tabular}

Source: Jubilee General Insurance (JGI).

The empanelled service providers did not have a Diagnostic Related Group (DRG) system for categorization of services utilized during inpatient admissions. Hence claims depended on individual categorization and reporting by the insurance provider, constraining a meaningful analysis. Utilization data shows that the highest utilization 
(18.9\%) was observed for obstetric and gynaecological care that included delivery, cesarean section, dilation and curettage (D\&C).; followed by management of infections (18.1\%) and gastroenteric diseases (Table 4). According to the MICS data, a significant number of women in these districts required hospital-based care for deliveries and many needed hospital-stays of between 1-3 days and longer (Table 2). The insurance scheme required at empanelled hospitals to have a maternity and gynaecology ward, a labor room and an operation theater to cover obstetrics care. This was followed by in-patient care sought for the management of infections, including acute respiratory infections, diarrhoea, vomiting, malaria, typhoid, hepatitis and pelvic inflammatory diseases. Chronic conditions such as liver and kidney diseases, anemia, chronic obstructive pulmonary disease (COPD) and gastroenteric diseases were some of the other conditions for which care was required at the empanelled facilities. Treatment was also sought for heatstroke and dehydration that can be common in the summer months given that the beneficiaries are mostly farmers working in the fields (Table 4). There was no data presenting gender breakdown utilization of services. However, women having the highest rate of hospitalization as noted by the number of cases belonging to the obstetrics and gynaecological category may indicate a step towards reducing gender inequality in the utilization of health care services offered by the MHI scheme.

Table 4. Types of claims received up to July 2018

\begin{tabular}{lll}
\hline Type of claim & Number of cases & \% of cases \\
\hline Obstetrics/gynecology & 353 & $18.9 \%$ \\
\hline Infections (URTI/LRTI /malaria/typhoid/UTI/hepatitis) & 339 & $18.1 \%$ \\
\hline Gastroenteric diseases & 280 & $15.0 \%$ \\
\hline Chronic kidney/ bladder disease & 77 & $4.1 \%$ \\
\hline Pelvic inflammatory disease & 60 & $3.2 \%$ \\
\hline Anemia & 46 & $2.5 \%$ \\
\hline Chronic liver disease & 44 & $2.4 \%$ \\
\hline Dehydration/heat stroke & 35 & $1.9 \%$ \\
\hline COPD & 29 & $1.6 \%$ \\
\hline Hemorrhoid & 26 & $1.4 \%$ \\
\hline
\end{tabular}

Source: Jubilee General Insurance (JGI).

Improving financial access: Users of MHI favorably reported the ability to access to obstetrics and gynaecological procedures which would not have been affordable otherwise. The availability of MHI cards encouraged communities to access qualified doctors and rely less on unlicensed informal providers available nearby. Also, those who used the cards reported that the MHI provided a buffer from financial shocks and helped save critical assets such as livestock from being sold to pay for healthcare. It also prevented them from resorting to borrowing money from landlords, neighbors and family.

"I am pleased and feel delighted that I had the MHI card for my caesarian delivery which I used in time to save my life."

"Truly, I was left nowhere when I came to know about my husband's ailment and the money required for the surgery-... thank God I had the health card... he is now living a normal life with the family. I have really no words to express gratitude for such great support."

Awareness issues: One of the most challenging tasks reported by the implementing NGO was transferring adequate communication to beneficiaries on how the insurance can be used to access hospitalization and how to use the health card at the hospital. The community needed to be educated "repeatedly and frequently" regarding the benefits plan and its utilization. It was also reported that since the beginning of the program, efforts of the RSPs had been focused on social mobilisation activities such as creating COs, linking them to VOs and LSOs. Efforts were mainly directed towards getting the women of the community to become members, and registering MHI beneficiaries, less attention, time and resources for quality interactions with the beneficiaries on the correct use of MHI card. Some confused the scheme with previous insurance schemes offering different benefits. Others even mistook the MHI cards for an automated teller machine (ATM) card thinking they could draw out up to Rs. 25000/- 
from an ATM machine. As a result, several MHI cards were recovered from ATMs. All these reasons led them to assume the card was fake and they cautioned other community members from trusting the scheme and using the card. Card holders who did not utilize the scheme also reported preferring government hospitals over empanelled private facilities due to the misinformation received from other users. In some, but fewer instances, cultural beliefs of some community members prevented them from accepting the card during distribution. They believed that if they take measures to pay for healthcare, disease and illness would come knocking at their door.

Moreover, medical camps by empanelled providers to create community awareness for the health card scheme tended to provide curative care rather than awareness-raising and communication. During the medical camps, the insurance staff distributed food supplements and toys, screened outpatients for chronic diseases referred them to health facilities for treatment. However, screening and referral was done for several diseases that were not covered by the MHI scheme. Hence a number of beneficiaries reported trying to use the card for out-patient services and being turned away.

"People get disappointed after finding out that treatment for diseases they were screened for (Hepatitis B, C, Diabetes and high blood pressure) in the medical camps were not covered by the insurance card".

"I am an MHI cardholder. My husband was sick, but my son preferred a government hospital for the treatment of his father....we thought we would be refused treatment at the private (empanelled) hospital. After a few days, my husband died in the government hospital."

Access snags at empanelled hospitals: In several instances, especially at the start of the scheme, the hospital staff were not made aware of the MHI contract between the hospital management and the insurance provider and so failed to recognize the card when shown. Instances such as these discouraged other MHI cardholders against the utilization of empanelled facilities. Moreover, there were also concerns from enrollees when visiting empanelled hospitals of unfriendly staff behavior and feeling stigmatized as the poor. At the time of admission, the MHI card and the insurance holder's CNIC was to be presented as per the guidance. However, if the patient seeking care was an eligible adult family member, their CNIC was also requested by the hospital staff as proof of relationship. In some instances, families did not carry CNICs and had to be denied treatment despite their eligibility. Some enrollees did not even possess a CNIC card and shared their frustration of not being able to benefit from it as they did not have a CNIC.

"Once we show MHI cards at the hospital reception, the staff says 'slum dwellers have come",

"We took our 4-year-old child suffering from a severe chest infection, fever and diarrhoea to an empanelled hospital. We were confident that MHI card will be helpful in this situation... we showed the doctor our MHI card but he did not recognise it and said if we had money then we could admit our daughter...otherwise, purchase medicines and go back home."

Physical Barriers to Accessing Empanelled Hospitals: Considerable variation in access was seen within districts. For example, within Jamshoro district the highest instance of utilization was noted in Jamshoro town center localities where the empanelled hospital was at a close distance to the district making it easily accessible by the beneficiaries. However, within the same district, the locality of Mole was approximately 5 hours away from the nearest empanelled hospital and showed the lowest utilization within the same district. The opportunity cost of traveling long distances was of high concern for beneficiaries living in remote villages. For daily wage earners and tenant farmers, the long travel and lack of public transport weighed against the loss of a day's income and the cost of hired transport was a key factor influencing utilization. It was observed that none of the cardholders knew of their entitlement to transport cost, nor were they provided with a transport allowance for their commute to the empanelled hospital. MHI staff involved in distributing the card to the community were also unaware of the transport cost coverage being part of the scheme as stated in the contract with the insurance provider. A staff member at the insurance provider admitted to not informing the beneficiaries of this allowance and blamed their lack of capacity for not disbursing travel allowance. According to them, they lacked the mechanism to calculate reasonable costs and therefore were unable to pay. They also admitted relying on low utilization during the initial years of the scheme to compensate for a rise in claims in the later years. For the insurance provider, this contract was an unusual one where the premium was fixed for 5 years and did not allow the usual annual increase.

"Over the five-year period of insurance, the premium of Rs. 1000/-per family remains fixed. We agreed to the signing of this contract expecting that the insurance utilization will be extremely low in the initial years owing to lack of awareness, low literacy and other factors."

MHI staff observed that insurance providers are required to set up at least one empanelled hospital in each of the programme districts to meet the requirements of the contract. They were also aware of some areas such as Mole 
that required traveling long distances to reach an empanelled facility and addressed the issue with the insurance provider. According to the insurance provider, the backup facilities in the remoter areas of the district were not favorable for setting up the empanelled hospital.

\section{Discussion}

In this paper, we analyzed secondary quantitative and qualitative data on the micro health insurance initiative currently underway in eight rural districts of Pakistan focusing on its utilization and the key factors influencing it. Analyzing experiences and perceptions is important to align initiatives with the users' unique needs to enable a positive experience and increase utilization of the scheme. The lessons learnt from schemes that take into account user journeys can serve as a platform to build on for designing and implementing a larger NHI programme such as the Sehat Sahulat program launched by the Government of Pakistan.

Our analysis of the utilization data found that even though the scheme catered to the health needs of the community and provided them with financial risk protection, utilization remained low. Highest utilization was for facility-based maternity care that included both complicated and uncomplicated deliveries. MHI alone may not be enough to improve maternal health, however, this MHI scheme appears to have made access to facility-based care and skilled birth assistance possible. This also indicates significant utilization by the female gender aligned with the women empowerment and gender equality objectives of the SUCCESS program. Global studies have shown similar outcomes (Bertakis, Azari, Helms, Callahan, \& Robbins, 2000; Koolman \& Alleyne, 2007). A deeper dive into the qualitative findings highlighted several barriers to utilization. The key barriers being i) lack of awareness and understanding of the scheme in the community; ii) the long travel required to reach the empanelled hospitals for several localities; and iii) access issues at facility level hampering utilization.

The community member, both users and non-users of the scheme, did not understand fully that the health insurance card was provided to them to protect them from catastrophic health care expenditure and the services it offered. This was not uncommon as similar experiences were noted for other schemes (Aji, De Allegri, Souares, \& Sauerborn, 2013; Aryeetey et al., 2016; H. T. Nguyen, Rajkotia, \& Wang, 2011; Prinja, Chauhan, Karan, Kaur, \& Kumar, 2017). However, users of the health card only valued it after they were able to use it successfully. Those who used the card, noted being saved from incurring debt on account of health care expenditure or in case of a larger payment risk catastrophic health expenditure. Lack of awareness also resulted in clients trying to access out-patient services; refusing to accept the card due to cultural beliefs; confusing the card with those of previous schemes; and mistaking it for an ATM card. All this fall under the 'awareness creation' umbrella that was not strongly and frequently linked with the scheme from the start. Employees State Insurance Corporation health camps at Bengaluru, India, suggest that repeated interaction with the community work to establish trust and develop understanding of the benefits of the scheme (Kusuma, Pal, \& Babu, 2018; Nagaraja et al., 2013).

The opportunity cost of traveling to empanelled hospitals that were a significant drive away for many localities came at the cost of their day's wage, with the additional expense of hired transport. These barriers to accessing care at empanelled hospitals were crucial to utilization. For these remote localities, it may be cost-effective to go to a nearby facility and pay out of pocket. Distance to the empanelled healthcare facility was found to be significant to utilization in several other global studies (Iqbal et al., 2017; Kusuma, Pal, \& Babu, 2018).

Access issues at facility level were uninformed, unfriendly hospital staff, stigmatization by the health facility staff on using the MHI card and issues with CNICs. The unpleasant experiences would result in a loss of trust in the scheme and decreased utilization. As a spillover effect of the negative experiences, others in the community would also avoid using the card for fear or being turned away. Similar barriers to utilization were reported by the Jamkesmas cardholders in Indonesia who preferred to pay out-of-pocket rather than be stigmatized for being poor (Vilcu, Probst, Dorjsuren, \& Mathauer, 2016) and in Rwanda where lack of interpersonal skill of the staff was cited as the major reason for underutilization (Schneider, 2005).

\section{Conclusion}

Our analysis highlights that utilization of the MHI is determined by the need, the understanding and willingness to seek care and finally the access to care. The MHI in rural Pakistan is suffering from a variety of operational difficulties such as inadequate policies and procedures in place which if not addressed might hamper its intended goal of increasing access to care and offering financial protection against the catastrophic cost of illness. There is a distinct need for continuous analysis of the schemes to fully understand the factors affecting utilization and the impact of financial protection mechanisms on the universal healthcare goal.

Our review calls for specific policy interventions to address the issues highlighted (i) a substantial increase in efforts and resources for awareness creation to improve insurance literacy and address the negative experiences in 
the community; (ii) efforts to improve physical access to facilities by building capacities of the non-empanelled facilities closer to remote areas in addition to the calculation and disbursement of transport allowance; and (iii) training the facility staff to be empathetic and respectful of all patients including the MHI card users and facilitate them in accessing care. The experience of MHI from Pakistan will contribute to informing ongoing efforts in other countries facing similar challenges in moving towards universal health care coverage.

\section{Competing Interests Statement}

The authors declare that there are no competing or potential conflicts of interest.

\section{References}

Abduljawad, A., \& Al-Assaf, A. F. (2011). Incentives for better performance in health care. Sultan Qaboos University medical journal, 11(2), 201-206. Retrieved from https://pubmed.ncbi.nlm.nih.gov/21969891

Aji, B., De Allegri, M., Souares, A., \& Sauerborn, R. (2013). The impact of health insurance programs on out-of-pocket expenditures in Indonesia: an increase or a decrease? International journal of environmental research and public health, 10(7), 2995-3013. https://doi.org/10.3390/ijerph10072995

AKDN. First Microinsurance Agency (FMiA)-Aga Khan Development Network. Retrieved from https://www.akdn.org/press-release/first-microinsurance-agency-established-pakistan

Aryeetey, G. C., Westeneng, J., Spaan, E., Jehu-Appiah, C., Agyepong, I. A., \& Baltussen, R. (2016). Can health insurance protect against out-of-pocket and catastrophic expenditures and also support poverty reduction? Evidence from Ghana's National Health Insurance Scheme. International Journal for Equity in Health, 15(1), 116. https://doi.org/10.1186/s12939-016-0401-1

Bertakis, K. D., Azari, R., Helms, L. J., Callahan, E. J., \& Robbins, J. A. (2000). Gender differences in the utilization of health care services. Journal of family practice, 49(2), 147-147.

Bitran, R. (2014). Universal health coverage and the challenge of informal employment: lessons from developing countries (English). Health, Nutrition, and Population (HNP) discussion paper. Washington DC; World Bank Group. Retrieved from http://documents.worldbank.org/curated/en/698041468180275003/Universalhealth-coverage-and-the-challenge-of-informal-employment-lessons-from-developing-countries

Bredenkamp, C., Evans, T., Lagrada, L., Langenbrunner, J., Nachuk, S., \& Palu, T. (2015). Emerging challenges in implementing universal health coverage in Asia. Social science \& medicine, 145, 243-248. https://doi.org/10.1016/j.socscimed.2015.07.025

Capuno, J. J., Kraft, A. D., Quimbo, S., Tan Jr, C. R., \& Wagstaff, A. (2016). Effects of price, information, and transactions cost interventions to raise voluntary enrollment in a social health insurance scheme: A randomized experiment in the Philippines. Health economics, 25(6), 650-662. https://doi.org/10.1002/hec.3291

Churchill, C. (2006). What is insurance for the poor? in C. Churchill (ed) Protecting the Poor: A Microinsurance Compendium, Geneva: ILO, pp. 12-24.

Churchill, C., \& McCord, M. J. (2012). Current trends in microinsurance. Protecting the poor: A microinsurance compendium, 2, 8-39.

Comfort, A. B., Peterson, L. A., \& Hatt, L. E. (2013). Effect of health insurance on the use and provision of maternal health services and maternal and neonatal health outcomes: a systematic review. Journal of health, population, and nutrition, 31(4 Suppl 2), S81.

Criel, B., \& Waelkens, M. P. (2003). Declining subscriptions to the Maliando mutual health organisation in Guinea-Conakry (West Africa): what is going wrong? Social science \& medicine, 57(7), 1205-1219. https://doi.org/10.1016/s0277-9536(02)00495-1

Government of Khyber Pakhtunkhwa. Sehat Sahulat program-KP. Retrieved from https://sehatsahulat.com.pk/

Government of Pakistan. Sehat Sahulat Program. Retrieved from https://www.pmhealthprogram.gov.pk/

Government of Pakistan. Waseela-e-Sehet. Retrieved from https://bisp.gov.pk/waseela-e-sehet/

Horton, R., \& Das, P. (2015). Universal health coverage: not why, what, or when-but how? The Lancet, 385(9974), 1156-1157. http://dx.doi.org/10.1016/ S0140-6736(14)61742-6

Iqbal, M., Chowdhury, A. H., Mahmood, S. S., Mia, M. N., Hanifi, S. M. A., \& Bhuiya, A. (2017). Socio-economic and programmatic determinants of renewal of membership in a voluntary micro health insurance scheme: 
evidence from Chakaria, Bangladesh. Global health action, 10(1), 1287398-1287398. https://doi.org/10.1080/16549716.2017.1287398

Jooma, R., \& Jalal, S. (2012). Designing the first ever health insurance for the poor in Pakistan-a pilot project. JPMA: Journal of the Pakistan Medical Association, 61(1), 56.

Khan, J. A., \& Ahmed, S. (2013). Impact of educational intervention on willingness-to-pay for health insurance: A study of informal sector workers in urban Bangladesh. Health economics review, 3(1), 12. https://doi.org/10.1186/2191-1991-3-12

Kimball, M., Phily, C., Folsom, A., Lagomarsino, G., \& Holtz, J. (2013). Leveraging health microinsurance to promote universal health coverage. Microinsurance Paper(23). Retrieved from https://www.findevgateway.org/paper/2013/01/leveraging-health-microinsurance-promote-universal-healthcoverage

Koolman, X., \& Alleyne, V. (2007). The Effect of Micro Health Insurance on Gender Inequity in Utilization of Health Care in India. Paper presented at the iHEA 2007 6th World Congress: Explorations in Health Economics Paper. Retrieved from https://research.vu.nl/en/publications/the-effect-of-micro-health-insurance-on-gender-inequity-in-utiliz

Kusuma, Y. S., Pal, M., \& Babu, B. V. (2018). Health Insurance: Awareness, Utilization, and its Determinants among the Urban Poor in Delhi, India. Journal of epidemiology and global health, 8(1), 69-76. https://doi.org/10.2991/j.jegh.2018.09.004

Levine, D., Polimeni, R., \& Ramage, I. (2016). Insuring health or insuring wealth? An experimental evaluation of health insurance in rural Cambodia. Journal of Development Economics, 119, 1-15. https://doi.org/10.1016/j.jdeveco.2015.10.008

Mathauer, I., Schmidt, J. O., \& Wenyaa, M. (2008). Extending social health insurance to the informal sector in Kenya. An assessment of factors affecting demand. The International journal of health planning and management, 23(1), 51-68. https://doi.org/10.1002/hpm.914

Meessen, B., Akhnif, E. H., Kiendrébéogo, J. A., Alaoui, A. B., Bello, K., Bhattacharyya, S., . . Kelley, A. G. (2019). Learning for Universal Health Coverage. BMJ Global Health, 4(6). https://doi.org/10.1136/bmjgh-2019-002059

Mehmood, A., Rowther, A. A., Kobusingye, O., \& Hyder, A. A. (2018). Assessment of pre-hospital emergency medical services in low-income settings using a health systems approach. International journal of emergency medicine, 11(1), 53. https://doi.org/10.1186/s12245-018-0207-6

MICS. (2014). Multiple Indicator Cluster Survey-Sindh. Retrieved from http://sindhbos.gov.pk/mics/

Nagaraja, S. B., Prakash, S., Kumbhar, S., Kiran, D., Phukan, P., Kumar, P., \& Menezes, R. G. (2013). Employees State Insurance Corporation health camps at Bengaluru, India: Bridging gaps. Indian journal of occupational and environmental medicine, 17(2), 78. http://doi.org/10.4103/0019-5278.123175

Naya Jeevan. Retrieved from https://naya-jeevan.com/

Nguyen, H. T., Rajkotia, Y., \& Wang, H. (2011). The financial protection effect of Ghana National Health Insurance Scheme: evidence from a study in two rural districts. International Journal for Equity in Health, 10(1), 4. https://doi.org/10.1186/1475-9276-10-4

Nguyen, H., \& Knowles, J. (2010). Demand for voluntary health insurance in developing countries: the case of Vietnam's school-age children and adolescent student health insurance program. Social science \& medicine, 71(12), 2074-2082. https://doi.org/10.1016/j.socscimed.2010.09.033

Panda, P., Chakraborty, A., \& Dror, D. M. (2015). Building awareness to health insurance among the target population of community-based health insurance schemes in rural India. Tropical Medicine \& International Health, 20(8), 1093-1107. https://doi.org/10.1111/tmi.12524

Prinja, S., Chauhan, A. S., Karan, A., Kaur, G., \& Kumar, R. (2017). Impact of publicly financed health insurance schemes on healthcare utilization and financial risk protection in India: a systematic review. PloS one, 12(2). https://doi.org/10.1371/journal.pone.0170996

Purohit, B. (2014). Community based health Insurance in India: prospects and challenges. Health, 2014. Retrieved from http://www.scirp.org/journal/PaperInformation.aspx?PaperID=46138

Reich, M. R., Harris, J., Ikegami, N., Maeda, A., Cashin, C., Araujo, E. C., . . Evans, T. G. (2016). Moving 
towards universal health coverage: lessons from 11 country studies. The Lancet, 387(10020), 811-816. https://doi.org/10.1016/S0140-6736(15)60002-2

RSPN. (2008-09). Rural Support Programmes Network-Annual Report. Retrieved from http://www.rspn.org/wp-content/uploads/2013/04/RSPN-Annual-Report-2009.pdf

Rural Support programme Network. (2016). Summary of Poverty Scorecard Survey in Sindh Union Council and Community Economic Strengthening Support (SUCCESS) Programme Districts. Retrieved from https://success.org.pk/wp-content/uploads/2016/08/SUCCESS-PSC-Baseline-Report.pdf

Rural Support programme Network. (2017-18). Women paving the way to success-Annual Key Performance $\begin{array}{llll}\text { Indicators } & (\mathrm{KPI}) & \text { report. } & \text { Retrieved }\end{array}$ https://success.org.pk/wp-content/uploads/2018/06/KPI-Report-2017-18.pdf

Rural Support programme Network. (2018a). Internal report-Micro Health Insurance Scheme.

Rural Support programme Network. (2018b). Self-Evaluation for the Mid-term Review: Sindh Union Council and Community Economic Strengthening Support (SUCCESS) Programme. Retrieved from https://success.org.pk/wp-content/uploads/2019/05/SUCCESS-Self-evaluation-Final-Report.pdf

Savedoff, W. D., de Ferranti, D., Smith, A. L., \& Fan, V. (2012). Political and economic aspects of the trasnsition to universal health coverage. The Lancet, 380(9845), 924-932. https://doi.org/10.1016/S0140-6736(12)61083-6

Schneider, P. (2005). Trust in micro-health insurance: an exploratory study in Rwanda. Social science \& medicine, 61(7), 1430-1438. https://doi.org/10.1016/j.socscimed.2004.11.074

Schneider, P., \& Diop, F. (2001). Synopsis of results on the impact of community-based health insurance on financial accessibility to health care in Rwanda: World Bank, Washington, DC. Retrieved from https://openknowledge.worldbank.org/bitstream/handle/10986/13798/289030Schneide1sis0of0Results1 who le.pdf? sequence $=1$

Tabor, S. R. (2005). Community-based health insurance and social protection policy. World Bank, Washington: Social Protection Discussion Paper Series. Retrieved from http://citeseerx.ist.psu.edu/viewdoc/download?doi=10.1.1.554.1192\&rep=rep1\&type=pdf

Taneja, P. K., \& Sihare, H. (2011). Pros \& cons of micro health insurance to eradicate health problems in the Below Poverty Line (BPL) population: empirical evidence from India. Italian Journal of Public Health, 8(4). https://doi.org/10.2427/5683

Thornton, R. L., Hatt, L. E., Field, E. M., Islam, M., Solís Diaz, F., \& González, M. A. (2010). Social security health insurance for the informal sector in Nicaragua: a randomized evaluation. Health economics, 19(S1), 181-206. https://doi.org/10.1002/hec.1635

United Nations. (2016). Sustainable Development Goal 3: ensure health lives and promote well-being for all at all ages. Retrieved from https://sustainabledevelopment.un.org/sdg3

Vilcu, I., Probst, L., Dorjsuren, B., \& Mathauer, I. (2016). Subsidized health insurance coverage of people in the informal sector and vulnerable population groups: trends in institutional design in Asia. International Journal for Equity in Health, 15(1), 165. https://doi.org/10.1186/s12939-016-0436-3

Wagstaff, A. (2007). Health insurance for the poor: initial impacts of Vietnam's health care fund for the poor: The World Bank. https://doi.org/10.1596/1813-9450-4134

Wagstaff, A., Nguyen, H. T. H., Dao, H., \& Bales, S. (2016). Encouraging health insurance for the informal sector: a cluster randomized experiment in Vietnam. Health economics, 25(6), 663-674. https://doi.org/10.1002/hec.3293

\section{Copyrights}

Copyright for this article is retained by the author(s), with first publication rights granted to the journal.

This is an open-access article distributed under the terms and conditions of the Creative Commons Attribution license (http://creativecommons.org/licenses/by/4.0/). 